\title{
LA MINORÍA DE EDAD PENAL Y SU NATURALEZA EN EL DERECHO BRASILEÑO
}

\author{
Roberto Barbosa Alves \\ Fiscal del Ministerio Público \\ del Estado de São Paulo \\ Doctor en Derecho Procesal \\ por la Universidad Complutense de Madrid \\ rbarbosaalves@uol.com.br
}

\begin{abstract}
RESUMEN
El trabajo plantea el análisis del Derecho penal brasileño en relación con los menores de edad, tanto en la tipificación de las conductas y su eventual responsabilidade criminal como en el cumplimiento de las penas y de las posibles medidas socioeducativas.
\end{abstract}

Palabras clave: Derecho penal, menores, penas, medidas socioeducativas, imputabilidad, responsabilidad.

\section{ABSTRACT}

This work assesses the study of Brazilian Penal Law concerning minors, whether in the criminally binding articles which describe penalties or social or academic prevention.

Keywords: Penal law, minors, socio-academic measures, criminal competence, criminal responsibility.

\section{ZUSAMMENFASSUNG}

Die vorliegende Arbeit untersucht das brasilianische Strafrecht in Bezug auf die Minderjährigen. Einbezogen wird hierbei sowobl die Typologisierung des Verbaltens und die eventuell daraus resulvierende Strafverantwortung als auch das Abbüßen der Strafe und die möglichen sozialerzieherischen Maßnabmen.

Schlüsselwörter: strafrecht, minderjährige, sozialerzieherische strafen, zuordenbarkeit, strafverantwortung. 
1. En este corto trabajo pretendemos plantear dos problemas: el primero, comprobar si el Derecho penal brasileño incide sobre los hechos practicados por los menores. Creemos que se puede responder afirmativamente sobre la base de la propia naturaleza penal — respecto a la forma, no al contenido- de las llamadas «medidas socioeducativas». En segundo lugar, verificar si el Derecho penal puede, desde la perspectiva constitucional de considerar inimputables a los menores, desarrollar su pleno potencial de prevención, por un lado, y de protección, por otro. Como argumentaremos, el reconocimiento de la ausencia de responsabilidad, siempre desde una perspectiva de la teoría general y de lege lata, antes de permitir que el Derecho penal despliegue su función de limitar la intervención del Estado -inherente al Estado democrático de Derecho- sobre el autor del delito, permite la imposición de una medida penal a partir del sencillo reconocimiento de un hecho típico ${ }^{1}$. Creemos, por ello, que habrá sido posible demostrar que la minoría de edad atrae —o al menos no aleja- el Derecho penal.

Sin embargo, no queda resuelta la cuestión de la naturaleza de la edad del agente frente a la práctica de un ilícito de carácter penal. Intentaremos sostener que la minoría de edad no puede incluirse entre las causas de falta de responsabilidad, sino que pertenece al ámbito de aplicación del Derecho procesal. Para llegar a esta conclusión, hemos tratado de traer para el ambiente de la ley brasileña de menores algunos elementos propios de la teoría general del Derecho procesal. Ahí encontramos un auténtico proceso, distinto al proceso penal y al proceso civil, exclusivamente a causa de sus distintos objetos. Situamos la edad del agente en el objeto del proceso, y en esta misma edad encontramos el potencial de inhibir la actuación del orden jurisdiccional «de adultos». Al final, ha sido posible atribuir a la menoridad la naturaleza de circunstancia modificativa de jurisdicción.

2. La doctrina brasileña suele afirmar que el Derecho de menores ha dado lugar al Derecho de la infancia y juventud. La opción tendría como fundamento el abandono de la doctrina de la situación irregular en favor de la doctrina de la protección integral. Consecuentemente, esto supon-

${ }^{1}$ En sentido diverso, pero desde otra perspectiva, la de la inimputabilidad como derecho individual de niños y adolescentes, fundada en la Constitución brasileña, Cfr. el trabajo de M. Toledo Machado, A proteção constitucional de crianças e adolescentes e os direitos humanos, Barueri, Manole, 2003, esp. pp. 197 y ss. Cfr. también, en el sentido de que la culpabilidad, en sí misma no constituye una garantía, sino el producto o síntesis del conflicto entre prevención, subsidiariedad y garantías individuales, J. M. Silva SÁncheZ, Aproximación al Derecho Penal contemporáneo, Barcelona, Bosch, 1997, pp. 293-296. 
dría la sustitución de la Justicia de Menores, tuitiva y paternalista, por una Justicia de la Infancia y Juventud adecuada al Derecho científico y a las normas constitucionales ${ }^{2}$.

De hecho, el Estatuto proscribe el término menor y adopta las expresiones niño y adolescente para definir, respectivamente, a las personas de hasta doce años de edad y a aquellas que tengan entre doce y dieciocho años (art. 2. ${ }^{\circ}$ ).

No existe unanimidad entre los investigadores con respecto a la aplicación del Derecho penal a los menores. Mensizábal Osés sostiene que «la acción reformadora que ha de impartir el Tribunal Tutelar, por su propia naturaleza, no es identificable con la idea de castigo» ${ }^{3}$. Entre los autores brasileños, Rebello Pinho defiende el antagonismo entre el Derecho penal y los menores de dieciocho años. Si el menor, dice, «requiere atención, apoyo y rehabilitación, su vinculación a la ley penal deberá reducirse a la definición de los delitos» ${ }^{4}$.

No consideramos correcta esta concepción. La característica básica del Derecho protector — privilegiar los intereses de los adolescentesno siempre garantiza los derechos fundamentales de los infractores, que a menudo pueden ser objeto de sanciones tan severas como las que se impondrían a un adulto. Por otra parte, el proceso simplemente tutelar nunca ha sido capaz de establecer la necesaria distinción entre los delincuentes y los niños abandonados, o entre los delitos más o menos graves.

Cualquier derecho de menores solo puede aplicarse incondicionalmente cuando esté basado en la idea de responsabilidad del adolescente infractor. Por otro lado, la finalidad del proceso por práctica de hecho delictivo debe ser la verificación de la práctica de un hecho penalmente típico. El proceso, y en particular la medida que corresponda, deberá considerar el orden educativo, pero también debe cumplir una función preventiva y punitiva concreta.

2 En España, defiende el nuevo modelo GONZÁLEz ZorRILla, «La justicia de menores en España», epílogo a la obra de G. DE LEO, La justicia de menores. La delincuencia juvenil y sus instituciones, Barcelona, Teide, 1985, p. 136, al afirmar que la necesidad de «modificar las bases de reacción institucional frente al fenómeno de la desviación infantil y juvenil requiere, entre otras cosas, desprenderse de la ideología positivista y correccionalista», y asimismo impone «recuperar todo el sentido garantista que en un Estado de derecho ha de rodear la imposición de sanciones, tengan el nombre que tengan».

${ }^{3}$ L. MendizÁbal Osés, Introducción al Derecho Procesal de menores, Madrid, Instituto de Estudios Políticos-Instituto de la Juventud, 1973, p. 137.

${ }^{4}$ R. Rebello Pinho, Menores infratores e criminosos imaturos, São Paulo, Max Limonad, 1969, p. 17. 
3. La comisión de un delito debe coincidir con una de las medidas educativas previstas en el art. 112 ECA (Estatuto da Criança e do Adolescente, o «Estatuto del Niño y del Adolescente»). Tales medidas dependen de un debido proceso, informado por todas las garantías constitucionales, indispensable la prueba de autoría y materialidad de la infracción. El proceso tiene destacada naturaleza jurisdiccional: la acción penal se desarrolla ante el juez, e incluso las posibilidades de transacción dependen de la aprobación judicial (arts. 181 y 182). El procedimiento está presidido por el contradictorio, que se materializa en las garantías de pleno conocimiento del hecho; de igualdad en la relación procesal, con la posibilidad de presentar las pruebas necesarias para su defensa; de defensa técnica y gratuita; de audiencia personal con el juez, y de exigir la presencia de los padres en cualquier etapa del procedimiento (art. 111). Por supuesto, no se excluyen las garantías propias del proceso penal (art. 152 ECA) y aquellos establecidos por la Constitución (art. 223, $\mathbb{3}$, IV y V).

Está claro, pues, que el legislador construyó un Derecho de la infancia y la juventud de carácter penal, templado por las características del adolescente como persona en desarrollo. Y las medidas educativas representan la manifestación del Estado en respuesta al hecho practicado por menores de dieciocho años, de naturaleza jurídica punitiva y retributiva, desarrolladas con un propósito pedagógico y educativo. No obstante, teóricamente con características diferentes de la cárcel, las medidas restrictivas impuestas al menor no pierden esta naturaleza, sea cual fuere el nombre que tengan. Es esencial, por tanto, que se aseguren al menor unos derechos constitucionalmente aplicables a los adultos. De hecho, el Derecho penal dispone de normas primarias propias, y una infracción es «penal» no porque se la sanciona con una pena, sino a causa de ciertas características materiales de la misma infracción.

4. La decisión según la cual un hecho es o no culpable es compleja: en ella deben concurrir consideraciones garantistas y preventivas. Roxin llega a diseñar una categoría autónoma al afirmar que la sanción solo puede ser determinada por la responsabilidad, que consiste en la suma de la culpabilidad con la necesidad de reacción, o, en otras palabras, de la culpabilidad del sujeto con la necesidad preventiva de la sanción penal, que debe deducirse de la ley.

Esta necesidad preventiva de la pena, que sin duda va a depender de juicios evaluativos de naturaleza político-criminal, se ajusta a los requisitos del Derecho de menores, que hace corresponder medidas socioeducativas a los autores de delitos. 
El Código Penal brasileño (arts. 26 y 27) declara exentos de responsabilidad criminal a determinados sujetos. La concepción es exclusivamente positivista y ubica en un mismo lugar incapacidades que tienen raíces muy distintas. La solución del legislador es, por tanto, criticable: el llamado loco, el que tiene alterada gravemente su conciencia de la realidad, y el menor, no pueden ocupar, sistemáticamente, un lugar común dentro del capítulo de las llamadas incapacidades, y, concretamente, en referencia a la incapacidad de culpabilidad.

Es cierto que la inimputabilidad es una ficción legal que opera como una presunción iuris et de iure y que, como tal, no admite prueba en contrario $^{5}$. De ahí que se pueda afirmar que la definición normativa de inimputabilidad es errónea: es necesario favorecer la responsabilidad del menor desde el plano jurídico-penal frente a la inimputabilidad ${ }^{6}$. El menor, por el simple hecho de ser menor, no deja de actuar libre y conscientemente. No penarlo «no tendría sentido alguno y tal vez delimitaría en el sujeto un sentido negativo de la justicia» ${ }^{7}$.

Atribuir responsabilidad al menor supone el establecimiento de una relación más clara y autónoma, tanto en función del ordenamiento jurídico como en función de la sociedad. La pena, en tanto no se creen las condiciones para su superación, no podrá ser eliminada, pero puede ser utilizada en un sentido social que permita un enfrentamiento claro entre el sujeto y el hecho cometido ${ }^{8}$. Esto ocurre porque «el joven que conoce y se condiciona y motiva hacia el respeto por las reglas del juego social hasta el punto de haberlas interiorizado espera, conforme a sus reglas, que en caso de violación de las normas sea justa la aplicación de una pena. No penar no tendría sentido alguno y tal vez delimitaría en el sujeto un sentido negativo de la justicia»?. Por el contrario, la anormalidad del menor lo excluye «de toda función garantística tanto en el plano sustantivo como en el plano procesal» ${ }^{10}$.

5. Rechazada, de lege ferenda, la minoridad penal como causa de inimputabilidad, queda por ubicar su naturaleza en el marco del Derecho procesal.

5 M. Cobo del Rosal y T. S. Vives Antón, Derecho penal, parte general, Valencia, Tirant lo Blanch, 1999, p. 603.

${ }^{6}$ R. CANTARERo, Delincuencia juvenil y sociedad en transformación transformación: derecho penal y procesal de menores, Madrid, Montecorvo, 1988, p. 122.

7 Ibid., p. 124, citando a Vercellone.

${ }^{8}$ Ibid., pp. 122-123.

9 Ibid., p. 124, citando a Vercellone.

${ }^{10}$ Ibid., p. 127. 
El ECA adopta un modelo procesal destinado al enjuiciamiento de hechos penalmente típicos practicados por los menores. Se trata de una verdadera ley de enjuiciamiento criminal de menores que adopta un procedimiento peculiar y utiliza todo el sistema de garantías constitucionales del proceso penal. Entre dos modelos posibles de tratamiento —el administrativo y el jurisdiccional—, optó el ordenamiento jurídico por el modelo de justicia de menores.

El carácter necesariamente protector de la Ley no es incompatible con la idea de una jurisdicción de menores. El proceso de menores se sustenta en el proceso penal, pero con notas específicas que el tratamiento de una persona en edad evolutiva exige. El legislador mantuvo para los menores un sistema procesal penal y sus conceptos, como la noción de notitia criminis, la peligrosidad social del actor, la responsabilidad civil ex delicto y la ejecución ${ }^{11}$. Pero el proceso, aunque esté apoyado sobre las bases del proceso penal, tiene unas características propias que requiere el tratamiento de una persona en proceso de desarrollo.

La concepción del proceso de menores que se utiliza del proceso penal, a pesar de las críticas que ha merecido a lo largo del tiempo ${ }^{12}$, «no deja de aportar indudables ventajas, en la medida en que el diseño procesal del menor participa de las características postconstitucionales, que asume el sistema procesal penal en general a través de una interacción exclusivamente procesal, que permite situar una parte de la ratio decidendi del nuevo diseño procesal del menor en la confluencia de las modernas características del sistema procesal penal en general» ${ }^{13}$. Si así es, nada queda en contra de un verdadero proceso de menores, ya que «es especialmente relevante para el interés del menor no solo el binomio proceso penal-derechos bumanos (del menor), sino la exclusión de la norma penal mediante un sistema procesal penal» ${ }^{14}$.

${ }^{11}$ G. LeONE, Elementi di diritto e procedura penale, Nápoli, Jovene, 1975, p. 188. En idéntico sentido, V. MANZINI, Istituzioni di diritto processuale penale, Padova, CEDAM, 1967, p. 13.

12 A. M. Lorca Navarrete, El proceso español del menor, Madrid, Dykinson, 1993, pp. 26-27. Analizando el sistema brasileño, objetó CAVALLIERI que también allí se impone al menor el sistema penal, con el pretexto de ofrecerle derechos y garantías del proceso de adultos: entre el proceso penal y el proceso de menores existe un simple cambio de palabras. Eso, a su parecer, significa un retroceso al año 1927, cuando la ley vigente establecía una acusación por el Ministerio Público y la defensa mediante abogado («O Estatuto e o menor infrator», Revista Ciência Jurídica, vol. 41, pp. 11-23, p. 11).

${ }_{13}$ A. M. LorCa NavarRete, El proceso español del menor, op. cit., p. 27.

${ }^{14}$ Ibid., p. 28. 
Tampoco sustrae el carácter tutelar de las leyes de menores la imposición de medidas por hechos establecidos en la legislación penal. Efectivamente, uno de los aspectos más positivos de la Ley de Menores está en que «se valora el hecho cometido y en función de él se interviene, ya que si no hay hecho no hay procedimiento, y se valora el autor, ya que es preceptiva, tras la comisión del hecho, la intervención de equipos técnicos de apoyo, integrados por psicólogos y educadores, que elaboran un informe sobre la situación psicológica, educativa y familiar del menor, así como su entorno social» ${ }^{15}$.

6. Por tanto, la jurisdicción penal es invocada a priori por un hecho - un ilícito de carácter penal-y luego es inhibida por la edad —la menoridad - del agente. Si es así, la menoridad penal tiene naturaleza procesal $\mathrm{y}$, de lege ferenda, no puede estar ubicada entre los motivos de inimputabilidad: la efectiva aplicación del ECA depende del reconocimiento de que el adolescente es responsable de sus actos, y esta responsabilidad constituye condición para la aplicación de las medidas socioeducativas. En conclusión, la exención de responsabilidad para los menores no configura una causa de inimputabilidad. Es, antes, una causa de inhibición de la jurisdicción en favor de los Juzgados de Menores en razón de una circunstancia modificativa de jurisdicción ${ }^{16}$. La consecuencia de esa modificación no será la exclusión del Derecho penal, sino la aplicación de medidas específicas que sustituyen con ventajas la necesidad de la pena.

15 F. de A. Sánchez MarTínez, Antecedentes y nuevo enjuiciamiento de menores: Ley 4/1992, Madrid, Marcial Pons, 1999, p. 165.

${ }_{16}$ F. Soto NieTo, «Preferencias e interferencias entre la jurisdicción especial de menores y la jurisdicción ordinaria», Revista general de legislación y jurisprudencia, 2." época, año CXII, t. XLIX, núms. 1-2 (1964), p. 435. 